\title{
The Effect of Heat Transfer Fluid Velocity on Heat Exchange Efficiency in Cold Energy Storage Tank: A Numerical Simulation Study
}

\author{
Xuan-Vien Nguyen ${ }^{1, *}$, Thanh-Hau Nguyen ${ }^{1}$, Trang-Doanh Nguyen ${ }^{1}$, Tien-Fu Yang ${ }^{2}$ \\ ${ }^{1}$ Renewable Energy Research Center, Department of Thermal Engineering, HCMC University of Technology and Education, Ho Chi Minh City, \\ Vietnam \\ ${ }^{2}$ Department of Energy and Refrigerating Air-Conditioning Engineering, National Taipei University of Technology, Taipei, Taiwan
}

Email address:

wienheating@gmail.com (Xuan-Vien N.), viennx@hcmute.edu.vn (Xuan-Vien N.), haunguyen1064@gmail.com (Thanh-Hau N.), trangdoanhnguyen@gmail.com (Trang-Doanh N.)

${ }^{*}$ Corresponding author

\section{To cite this article:}

Xuan-Vien Nguyen, Thanh-Hau Nguyen, Trang-Doanh Nguyen, Tien-Fu Yang. The Effect of Heat Transfer Fluid Velocity on Heat Exchange Efficiency in Cold Energy Storage Tank: A Numerical Simulation Study. Journal of Energy and Natural Resources.

Vol. 9, No. 2, 2020, pp. 70-74. doi: 10.11648/j.jenr.20200902.13

Received: April 14, 2020; Accepted: May 5, 2020; Published: May 14, 2020

\begin{abstract}
Developing a cold thermal energy storage (CTES) technology is one of the most effective methods to solve energy shortage and environmental pollution all over the world. The current study deals with the modelling and simulation of a cold thermal energy storage tank consisting of an polyvinyl chloride pipe (PVC) heat exchanger partially filled with a phase change material (PCM). Water, as the heat transfer fluid (HTF), flows through the inner tubes and the outer one while propylene glycol as the phase change material fills. This paper focuses on studying the effect of the velocity characteristics on the heat transfer efficiency of polyvinyl chloride pipe (PVC) heat exchanger in cold thermal energy storage system by the numerical simulation. In this paper, the detail of heat transfer performance within the heat exchanger is numerically solved using computational fluid dynamics (CFD), for various velocity as well as different heat transfer for optimal design. Several results of changes in the temperature field at the outlet of the cold thermal energy storage tank are presented when the inlet water velocity changes from 1 $\mathrm{m} / \mathrm{s}$ to $1.4 \mathrm{~m} / \mathrm{s}$. The results indicate that low input water velocity will provide better heat exchange efficiency. However, it is required to make sure that the flow inside the heat exchanger is the turbulent flow because the study uses turbulent flow modules.
\end{abstract}

Keywords: Cold Thermal Energy Storage, Numerical Simulation, Heat Exchanger, Computational Fluid Dynamics, Energy Saving, Air-conditioning

\section{Introduction}

Cold thermal energy storage (CTES) technology is one of the most effective methods to solve energy shortage and environmental pollution all over the world. The cold storage system has been mentioned in the energy saving field for a long time and much concerned by many scientists. Alva et al. [1] summarized and provided an overview of the classification, physical properties, cost, performance and conformity with installation requirements when applying each cold storage system in practice. In terms of expenses, the cold storage system can reduce power consumption cost, initial investment cost due to the smaller size of the chiller and associated equipment such as cooling towers, pumps, fans, piping system. The smaller system comes with many benefits on construction and architectural, power supply system designs, etc. Even in case of expanding the old system, the cold storage system can be still used instead of installing one more new chiller system [2]. Arcuri et al. [3] evaluated the ice storage system for commercial buildings in Brazil, they found that an ice storage system can help the commercial buildings effectively meet peak load, gaining economic benefits of saving energy. However, the economic efficiency of the cold storage system is not much in hospitals and hotels.

Teggar et al. [4] simulated a heat exchanger with a phase 
change agent in cold storage. In this process, the device solidified water and the water between two low-temperature plates with ethylene glycol as a refrigerant. After being compared with an experimental model, the simulation results are, in general, relatively close to the values obtained in the experiment. Zheng et al. [5] simulated the number of melting processes of the ice-on-coil cold storage system. They found that coils of larger diameters could result in better heat transfer under the same working conditions. Ensuring a heat transfer coefficient of the coil higher than that of ice could improve the thermal efficiency. Wu et al. [6] designed an ice storage for a building by storing ice during off-peak hours and using ice's heat during normal operating hours and peak hours. The system had two operating modes, ice formulation mode and cooling mode. Compared to a conventional water chiller the cold storage system needs to pay particular attention to predicting load at peak hours to be able to reduce capacity of system because with the same cooling capacity, a cold storage system only need a chiller of $70 \%$ capacity compared to a conventional chiller, thereby saving costs while still meeting the cooling requirements.

F. Fornarelli et al. [7] performed a digital simulation of the entire charging and discharging process of a coil type energy storage device with external phase-changing agent and internal refrigerants. The entire study consisted of 3 phases: the stable phase agent temperature phase, charging phase and discharging phase with simulation error of approximately $5 \%$ compared with experimental results. The study identified the shape, position of the phase transition area in the charging phase and mainly calculated during the charging and convection heat transfer processes. In addition, based on the temperature distribution during the discharging, it could be seen that convection heat transfer did not occur but the heat transfer process was mainly the conduction process when the phase-changing agent was melted. It seemed that the convection was limited by the geometric properties of the device in the study. S. Paria et al. [8] conducted on the processes of a stationary phase change material (PCM) in a shell around a finned-tube heat exchanger system based on experimental and numerical simulation. The results indicated that, by increasing the Reynolds number from 1000 to 2000, the total melting time decreases by $58 \%$. Tao et al. [9] studied the influence of natural convection and the fins on performance of horizontal latent heat storage tank. The indicated that the high temperature molten saltflows upward which enhances the phase change material melting rate in upside and weakens the melting rate in downside due to the effects of natural convection. Mao et al. [10] conducted on a 2D physical and mathematical model of a novel truncated cone shell-and-tube thermal energy storage tank. The results showed that the inlet temperature and velocity of heat fluid have the significant influence on the charging and discharging performance of thermal energy storage tank. et al. [11] studied on the modelling and simulation of a thermal energy storage unit consisting of an aluminum tank partially filled with a phase change material. The results showed that the conduction based model was not appropriate for the considered cold energy storage application since free convection plays a crucial role in the heat transfer inside the liquid phase change material.

Esapuor et al. [12] investigated the melting of a phase change material (PCM) in a multitube heat exchanger. The results showed that as the inlet temperature increases melting process accelerates and complete melting time reduces, whereas, similar mass flow rate increase does not reduce the melting time to such an extent. Wang et al. [13] simulated the effects of temperature difference between the inlet of heat transfer fluid and melting point of phase change material. results showed that charging and discharging processes have three stages for the change of temperature regarding to time PCM and heat charging or discharging rate regarding to time: rapidly changing period, slowly changing period and more slowly changing period. Saeid Seddegh et al. [14] the thermal behavior and heat transfer characteristics of a vertical cylindrical shell and tube latent heat thermal energy storage unit. The results indicated that the combined convection and conduction model can better describe the energy transfer in the phase change materials during melting process.

In this study, a model is built to numerically investigate the effects of velocity of the heat transfer fluid. The detail of heat transfer performance within the heat exchanger is numerically solved using computational fluid dynamics (CFD), for various velocity as well as different heat transfer for optimal design.

\section{Methodology}

\subsection{Geometry of Cold Thermal Energy Storage Tank}

The steel is used to fabricate the tank. The used material in heat exchanger of cold storage tank is polyvinyl chloride pipe (PVC) which is partially filled with a phase change material (PCM). The heat exchanger consists of nine branchs which are connected from upper manifold to lower manifold. Each branch has nine rows of pipe. The design of heat exchanger of cold storage tank is shown in Figure 1. Water, as the heat transfer fluid (HTF), flows through the inner tubes and the outer one while propylene glycol as the phase change material fills. The cold storage tank temperature is $271 \mathrm{~K}$, the inlet water temperature is $285 \mathrm{~K}$. The geometric parameters of cold storage tank are shown in Table 1.

Table 1. Geometric parameters.

\begin{tabular}{ll}
\hline Parameters & Dimensions \\
\hline Tank length $(\mathrm{L})$ & $2950 \mathrm{~mm}$ \\
Tank width $(\mathrm{W})$ & $1800 \mathrm{~mm}$ \\
Tank height $(\mathrm{H})$ & $1780 \mathrm{~mm}$ \\
Outer diameter of PVC pipe $\left(\mathrm{d}_{2}\right)$ & $21.4 \mathrm{~mm}$ \\
Inner diameter of PVC pipe $\left(\mathrm{d}_{1}\right)$ & $18.2 \mathrm{~mm}$ \\
Distance between centers of PVC pipes (width view) & $200 \mathrm{~mm}$ \\
Distance between centers of PVC pipes (height view) & $135 \mathrm{~mm}$ \\
Upper manifold diameter $\left(\Phi_{1}\right)$ & $150 \mathrm{~mm}$ \\
Lower manifold dimensions & $300 \times 150 \times 1800 \mathrm{~mm}$ \\
\hline
\end{tabular}




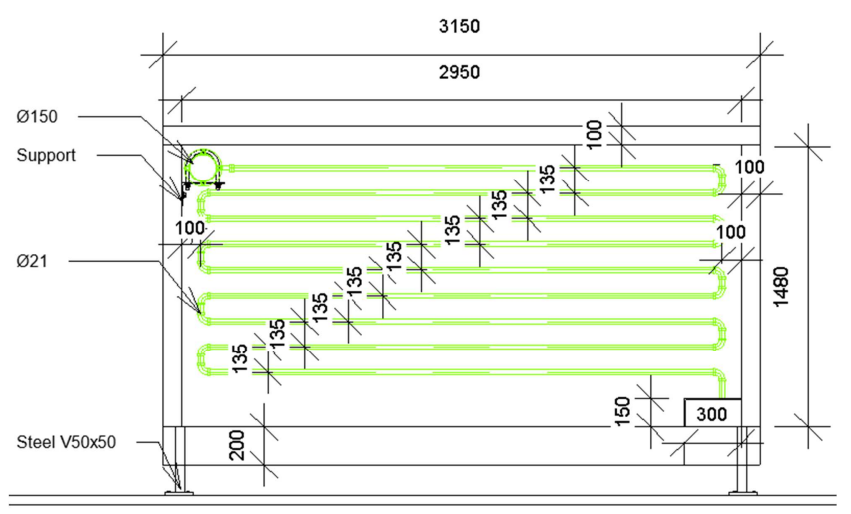

Figure 1. The design and dimensions of cold storage tank.

\subsection{Mathematic Equations}

The present study seeks to examine the fluid flow and heat transfer within a heat exchanger. The governing equations including the mass conservation (continuity), momentum conservation, and energy conservation equations are as the following:

Mass conservation (continuity) equation:

$$
\frac{\partial \rho}{\partial t}+\nabla \cdot(\rho \vec{v})=0
$$

Momentum conservation equation:

$$
\frac{\partial}{\partial t}(\rho \vec{v})+\nabla \cdot(\rho \vec{v} \vec{v})=-\nabla p+\rho g+\vec{f}
$$

Energy conservation equation:

$$
\frac{\partial}{\partial t}[\rho e]+\nabla \cdot[(\rho e+p) \vec{v}]=\nabla \cdot\left(k_{e f f} \nabla T-\sum_{j} h_{j} \vec{J}_{j}+\left(\vec{\tau}_{e f f} \cdot \vec{v}\right)\right)
$$

where $t$ is the time, $\rho$ is the mass density, $\vec{v}$ stands for the flow velocity, $p$ is the fluid pressure, $e$ is the inside energy per unit mass, $\vec{f}$ shows the volumetric force, $k_{\text {eff }}$ is the thermal conductivity, $h_{\mathrm{j}}$ is the enthalpy of species $j, \overrightarrow{J_{j}}$ represents the diffusion flux of species $j$ and finally $\vec{\tau}_{\text {eff }}$ exhibits the stress tensor.

The partial differential equations governing the fluid flow and heat transfer for turbulent water flow inside the absorber includes the continuity, Navier-Stokes energy equations and RNG k- $\varepsilon$ model. The energy equations are based on the resolution of the analytical model that includes the continuity, mass and energy conservation equations associated with two transport equations for $\mathrm{k}-\varepsilon$ model to calculate the turbulent energy production $\mathrm{k}$, and the turbulent energy dissipation $\varepsilon$.

\subsection{Mesh Generation}

One of the most important parts of simulation process is selecting a suitable meshing process to calculate fundamental governing equations the heat exchanger operation. Selecting a proper meshing can contribute to a suitable convergence in solving the equations while an improper meshing can lead to instability and divergence of calculations. Therefore, a structured hexahedral mesh algorithm was applied throughout the whole heat exchanger, for this type of mesh produces more reliable results due to its logical aspect ratios and skewness. Furthermore, as this type of mesh is less diffusive than the other types, doubtlessly it protects the results of simulation from any inaccuracy. The model is then exported for meshing, which is a process where the model is divided into a finite number of smaller with approximately 1000000 elements. The computational domain and mesh of model is shown in Figure 2.

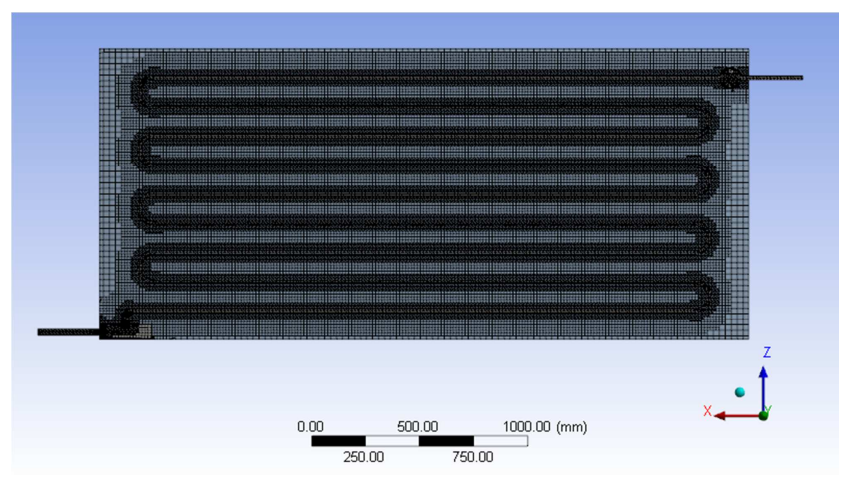

Figure 2. Computational domain and mesh.

\section{Results and Discussion}

With the simulation conditions mentioned in the previous section, when the velocity of water passing through the storage tank is changed from $1 \mathrm{~m} / \mathrm{s}$ to $1.4 \mathrm{~m} / \mathrm{s}$, the outlet temperature of the water also increases gradually from $282.4 \mathrm{~K}$ to $283.1 \mathrm{~K}$ (as shown in Figure 3 ). The results showed that when increasing evenly the velocity of inlet water, the temperature of outlet water also increases but increases unevenly. At the inlet velocity of from $1 \mathrm{~m} / \mathrm{s}$ to $1.1 \mathrm{~m} / \mathrm{s}$ or from $1.2 \mathrm{~m} / \mathrm{s}$ to $1.3 \mathrm{~m} / \mathrm{s}$, from $1.3 \mathrm{~m} / \mathrm{s}$ to $1.4 \mathrm{~m} / \mathrm{s}$, the temperature varied by $0.1 \mathrm{~K}$. When the inlet velocity is 1.2 $\mathrm{m} / \mathrm{s}$, the temperature increase is $0.5 \mathrm{~K}$, causing a strong fluctuation at this value. The simulation results also showed that at all five inlet velocity values at the start of discharging ice, the outlet water temperature droped rapidly by $4 \mathrm{~K}$ then stabilizes (as shown in Figure 4).

The results show the inlet water velocity gradually increases from $1 \mathrm{~m} / \mathrm{s}$ to $1.1 \mathrm{~m} / \mathrm{s} ; 1.2 \mathrm{~m} / \mathrm{s} ; 1.3 \mathrm{~m} / \mathrm{s} ; 1.4 \mathrm{~m} / \mathrm{s}$, the temperature field also changes. At the velocity of $1 \mathrm{~m} / \mathrm{s}$, the temperature reaches $283 \mathrm{~K}$ at the end of the fifth coil section from the bottom (as shown in Figure 5). As shown in Figure 6 , at $1.1 \mathrm{~m} / \mathrm{s}$, this temperature is reached at the middle of the fourth coil section from the bottom. Similarly at the velocity of 1.2 to $1.4 \mathrm{~m} / \mathrm{s}$, the position of water flow at $283 \mathrm{~K}$ temperature gradually recedes to the bottom of the heat exchanger (as shown in Figures 7, 8, 9, respectively). This result is also consistent with the change in outlet water temperature as shown above. 


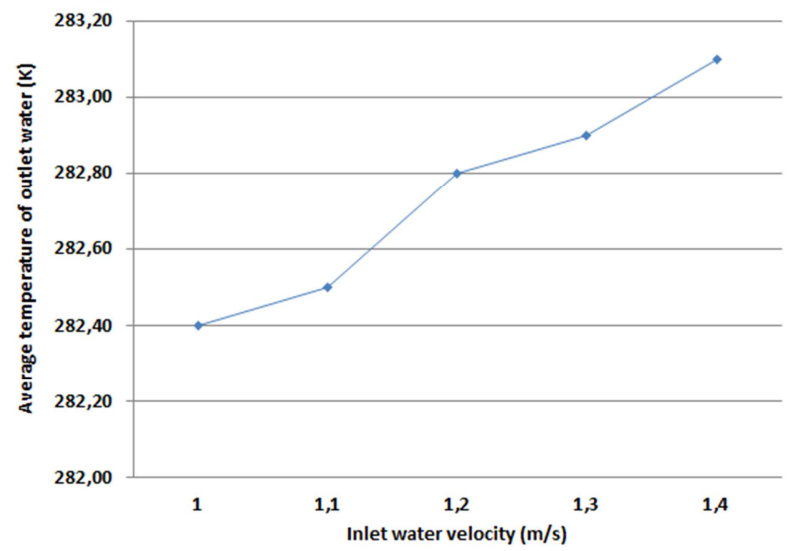

Figure 3. The chart of the effect of inlet velocity on the outlet water temperature.

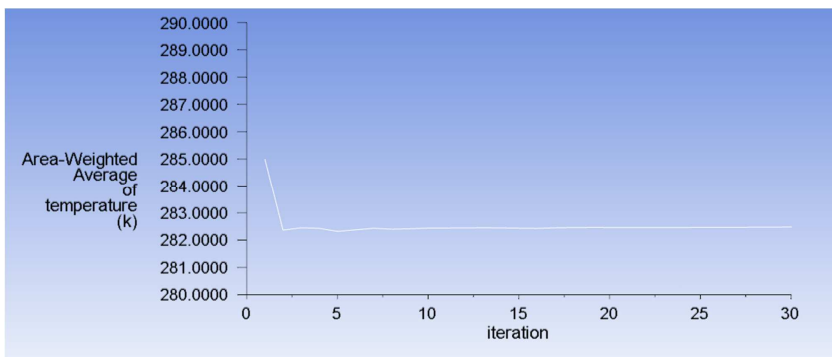

Figure 4. The change of the outlet water temperature

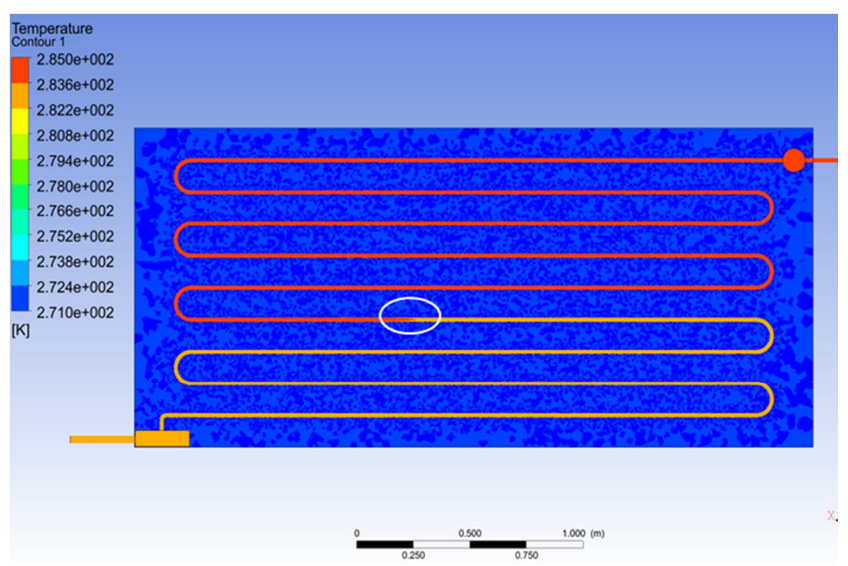

Figure 5. The temperature field at $1 \mathrm{~m} / \mathrm{s}$.
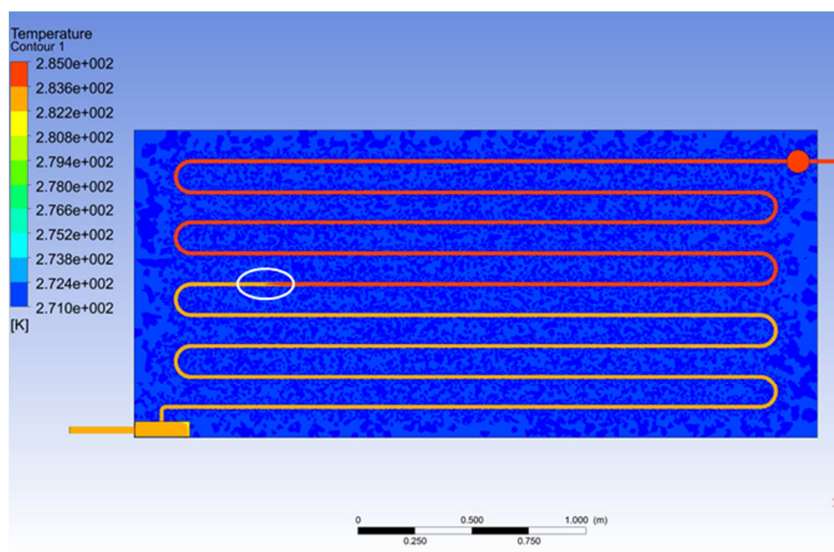

Figure 6. The temperature field at $1.1 \mathrm{~m} / \mathrm{s}$.

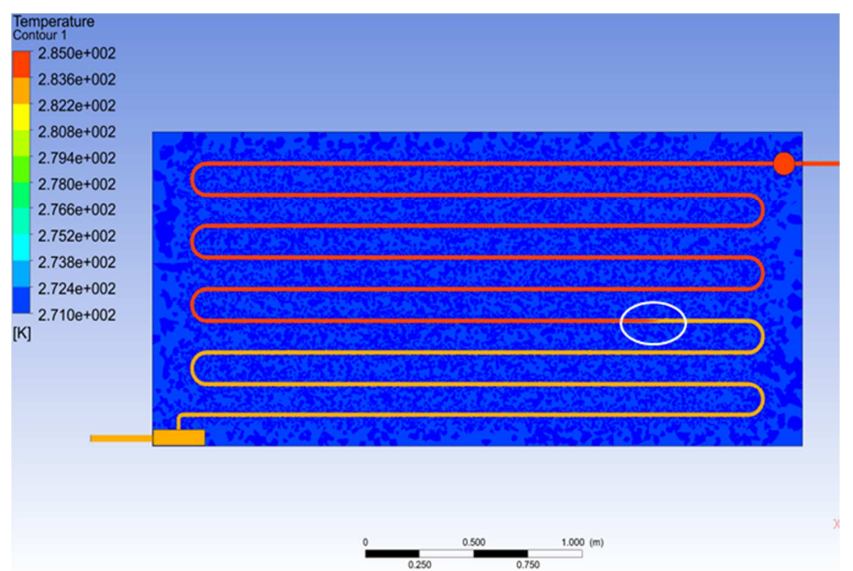

Figure 7. The temperature field at $1.2 \mathrm{~m} / \mathrm{s}$.

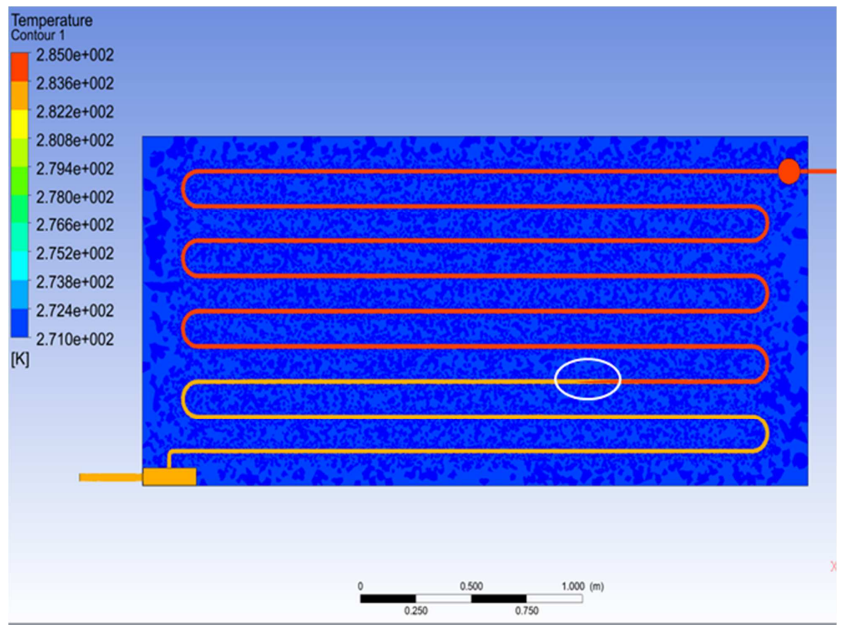

Figure 8. The temperature field at $1.3 \mathrm{~m} / \mathrm{s}$.

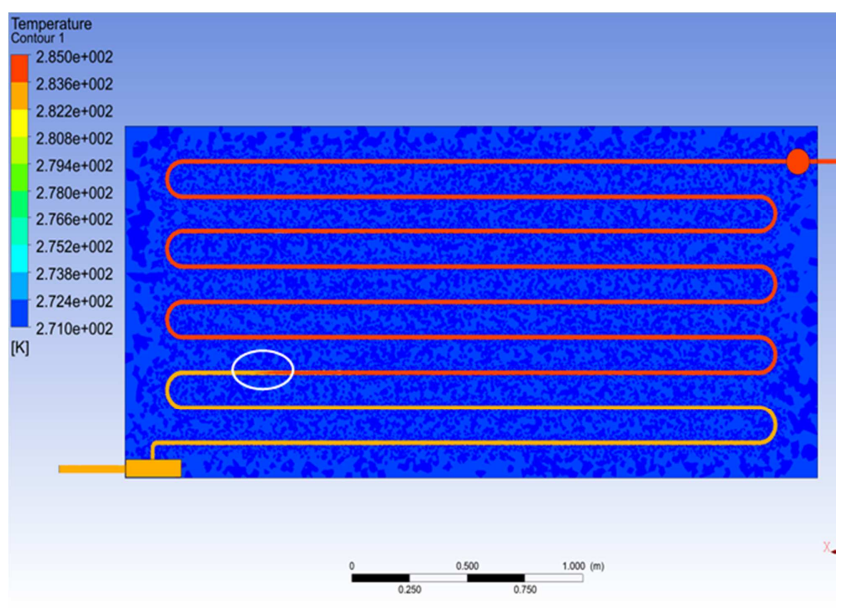

Figure 9. The temperature field at $1.4 \mathrm{~m} / \mathrm{s}$.

\section{Conclusion}

The effect of the inlet water velocity on the characteristics of the internal temperature field and the outlet of the heat exchanger has been studied by the numerical simulation method. The results have been shown and evaluated. The simulation conditions in this study have shown that low input water velocity will provide better heat exchange efficiency. 
However, it is required to make sure that the flow inside the heat exchanger is the turbulent flow because the study uses turbulent flow modules.

\section{Conflicts of Interest Statement}

All the authors do not have any possible conflicts of interest.

\section{Acknowledgements}

The authors would like to thank the Vietnam Ministry of Education and Training (Project No. B2019-SPK-02; Contract No. $02 / \mathrm{HĐKHCN)}$ for the financial support. In addition, the authors also thank all members of the Department of Thermal Engineering, HCMC University of Technology and Education for the support.

\section{References}

[1] Alva G, Lin Y, Fang G. An overview of thermal energy stogare systems. Energy 144 (2018); 341-378.

[2] He B, Setterwall F. Technical grade paraffin waxes as phase change materials for cool thermal storage and cool storage systems capital cost estimation. Energy Conversion and Management 43 (2002); 1709-1723.

[3] Arcuri B, Spataru C, Barrett M. Evaluation of Ice Thermal Energy Storage (ITES) for commercial buildings in cities in Brazil. Sustainable Cities and Society 29 (2017); 178-192.

[4] Teggar M, Mezaache E. H. Numerical Investigation of a PCM Heat Exchanger for Latent Cool Storage. Energy Procedia 36 (2013) 1310-1319.

[5] Zheng Z. H, Ji C, Wang W. X. Numerical Simulation of Internal Melt Ice-on-Coil Thermal Storage System. Engergy Procedia 12 (2011); 1042-1048.
[6] Wu C. T, Tsai Y. H. Design of an ice thermal energy storage system for a building of hospitality operation. International Journal of Hospitality Management 46 (2015); 46-54.

[7] Fornarelli F, Ceglie V, Fortunato B, Camporeale S. M, Torresi M, Oresta P, Miliozzi A. Numerical simulation of a complete charging-discharging phase of a shell and tube thermal energy storage with phase change material. Energy Procedia 126 (2017); 501-508.

[8] S. Paria, A. A. D. Sarhan, M. S. Goodarzi, S. Baradaran, and et al. Indoor solar thermal energy saving time with phase change material in a horizontal shell and finned-tube heat exchanger. The Scientific World Journal 15 (2015); 1-7.

[9] Y. B. Tao and Y. L. He. Effects of natural convection on latent heat storage performance of salt in a horizontal concentric tube. Applied Energy 143 (2015); 38-46.

[10] Qianjun Mao, Ning Liu, and Li Peng. Numerical investigations on charging/discharging performance of a novel truncated cone thermal energy storage tank on a concentrated solar power system. International Journal of Photoenergy (2019); 1-17.

[11] Luigi Mongibello, Nicola Bianco, Martina Caliano and Giorgio Graditi. Numerical simulation of an aluminum container including a phase change material for cooling energy storage. applied system innovation 1 (2018); 1-11.

[12] Esapour, M., Hosseini, M. J., Ranjbar, A. A., Pahamli, Y., Bahrampoury, R. Phase change in multi-tube heat exchangers. Renewable Energy 85 (2016); 1017-1025.

[13] Wei-WeiWang, Kun Zhang, Liang-Bi Wang, Ya-Ling He. Numerical study of the heat charging and discharging characteristics of a shell-and-tube phase change heat storage unit. Applied Thermal Engineering 58 (2013); 542-553.

[14] Saeid Seddegh, Xiaolin Wang, Alan D. Henderson. Numerical investigation of heat transfer mechanism in a vertical shell and tube latent heat energy storage system. Applied Thermal Engineering 87 (2015); 698-706. 